\title{
O Grupo de Pesquisa em Educação Algébrica (GPEA): mapeamento de algumas de suas produções
}

\author{
The Research Group in Algebraic Education (GEPA): the mapping of a number of
} its productions

\author{
BARBARA LUTAIF BIANCHINI ${ }^{1}$ \\ GABRIEL LOUREIRO DE LIMA ${ }^{2}$ \\ SILVIA DIAS ALCÂNTARA MACHADO ${ }^{3}$
}

\begin{abstract}
Resumo
O objetivo, neste artigo é, com base em dissertações e teses defendidas por membros do Grupo de Pesquisa em Educação Algébrica (GPEA), de 2003 a 2018, mapear alguns aspectos dessas produções, tais como, conteúdo matemático, objetivo, tipo de produção (dissertação ou tese), nível de ensino, sujeitos (no caso de pesquisas experimentais) $e$ documentos analisados. O corpus inicial da investigação constitui-se de 93 dissertações e 18 teses, mas, neste estudo, como nos detivemos às produções relativas aos cinco conteúdos matemáticos mais explorados, quais sejam, Números e Operações, Generalização de Padrões, Função, Álgebra Linear e Equações, analisamos 62 produções, 54 dissertações e oito teses. Por meio do exame realizado, notamos uma diversidade de temas ou conteúdos matemáticos explorados pelos pesquisadores do GPEA, o que indica a permeabilidade da Álgebra em diferentes campos da Matemática. A análise revela, entre outros aspectos, que, em relação às pesquisas experimentais, há demanda por mais investigações que estabeleçam relação entre os processos de ensino e de aprendizagem dos conteúdos matemáticos anteriormente citados e a utilização de Tecnologias Digitais de Informação e Comunicação. Quanto às pesquisas documentais, há necessidade de investigações que considerem uma maior diversidade de materiais, além de livros didáticos, dissertações e teses, para a produção de dados.
\end{abstract}

Palavras-chave: Grupo de Pesquisa em Educação Algébrica; Mapeamento; Dissertações; Teses.

\begin{abstract}
Based on dissertations and theses produced by members of the Research Group in Algebraic Education (GEPA), the objective of this article is to map some aspects of these productions, such as: mathematical content, objective, type of production (dissertation or thesis), level of education, subjects (in the case of experimental studies) or analyzed documents. The initial corpus of investigation is constituted by 93 dissertations and 18 theses, but in this article, as we worked on productions related to

\footnotetext{
${ }^{1}$ Doutora em Educação: Psicologia, PUC-SP, departamento de Matemática, barbara@ pucsp.br

${ }^{2}$ Doutor em Educação Matemática, PUC-SP, departamento de Matemática, gllima@ pucsp.br

${ }^{3}$ Doutora em Matemática: sem vínculo, silvia.puc.dam@gmail.com
} 
the five mathematical contents most explored: Numbers and Operations, Generalization of Patterns, Function, Linear Algebra and Equations, we analyzed 62 productions, of which 54 were dissertations and eight were theses. Based on the study held, we noted that a diversity of themes and mathematical contents were explored by the researchers of GPEA, indicating the permeability of Algebra em different fields of Mathematics. Regarding experimental studies, the analysis reveals, among other aspects, that there is a demand for more investigations related to the processes of the learning and teaching of the mathematical contents previously mentioned and the use of Digital Technologies of Information and Communication. For the documental studies, investigations considering a wider diversity of materials, beyond workbooks, dissertations and theses are required to produce data.

Keywords: Research Group in Algebraic Education, Mapping, Dissertations, Theses.

\section{Introdução}

Em 2019, durante a defesa de uma tese de doutorado de um membro do Grupo de Pesquisa em Educação Algébrica (GPEA), um dos examinadores, o professor doutor Francisco César Polcino Milies ${ }^{4}$, indicou-nos a importância de sintetizar os resultados das pesquisas sobre Educação Algébrica obtidos pelo Grupo desde seu início em 2003. Isso nos inspirou a realizar a investigação aqui apresentada, cujo objetivo é, com base em dissertações e teses defendidas por membros do GPEA, de 2003 a 2018, mapear alguns elementos presentes nessas produções, a saber: conteúdo matemático em foco, objetivo, tipo de produção (dissertação ou tese), nível de ensino, sujeitos (no caso de pesquisas experimentais) e documentos analisados.

Nossa intenção ao realizar esse mapeamento, conforme metodologia de Fiorentini, Passos e Lima (2016), é evidenciar à comunidade de Educação Matemática interessada em questões relacionadas ao ensino e à aprendizagem de Álgebra, bem como aos próprios membros do GPEA, os temas mais explorados nas investigações, aqueles que demandam novos estudos e, especialmente, lacunas existentes e caminhos ainda não percorridos que podem indicar direções para pesquisas futuras relativas à Educação Algébrica. Além disso, trabalhos como o aqui apresentado, que certamente terá continuidade por meio do mapeamento de outros elementos por parte do Grupo, oferecem aos educadores matemáticos sínteses e inventários de posicionamentos, quadros de referências e concepções do GPEA acerca do ensino e da aprendizagem de Álgebra.

\footnotetext{
4 Professor titular do Departamento de Matemática do Instituto de Matemática e Estatística da Universidade de São Paulo.
} 
Antes de efetivamente apresentar o mapeamento realizado, discorremos sobre o histórico do GPEA e sobre os projetos de pesquisa desenvolvidos, assim como aqueles em andamento no âmbito do Grupo; posteriormente, explicitamos a metodologia empregada nesta investigação.

\section{Grupo de Pesquisa em Educação Algébrica: suas origens e projetos de pesquisa}

O GPEA constituiu-se como Grupo de Pesquisa, vinculado ao Programa de Estudos Pós-Graduados em Educação Matemática da Pontifícia Universidade Católica de São Paulo (PUC-SP), em 2003. Inicialmente, seus membros eram os seguintes professores: Silvia Dias Alcântara Machado, Maria Cristina de Souza Albuquerque Maranhão, Sonia Pitta Coelho, Leila Zardo Puga e Barbara Lutaif Bianchini que, na ocasião, orientavam pesquisas voltadas ao ensino e à aprendizagem de Álgebra nos diferentes níveis de ensino.

Ao longo dos 16 anos de atividades do Grupo, foram desenvolvidos 20 projetos de pesquisa, considerando-se os finalizados e os em andamento, cujos títulos, tempo de duração e objetivos são apresentados no Quadro 1.

Quadro 1 - Projetos de pesquisa finalizados ou em andamento no âmbito do GPEA

\begin{tabular}{|c|c|c|}
\hline Título do Projeto & $\begin{array}{l}\text { Período de } \\
\text { Realização }\end{array}$ & Objetivo \\
\hline $\begin{array}{l}\text { Sobre o desenvolvimento } \\
\text { da noção de base de um } \\
\text { espaço vetorial }\end{array}$ & $2002-2006$ & $\begin{array}{l}\text { Investigar como abordar o objeto matemático } \\
\text { base de um espaço vetorial, de modo a } \\
\text { propiciar sua compreensão pelo aluno } \\
\text { ingressante no Ensino Superior. }\end{array}$ \\
\hline $\begin{array}{l}\text { O Teorema Fundamental } \\
\text { da Aritmética e o } \\
\text { cotidiano escolar }\end{array}$ & $2002-2005$ & $\begin{array}{l}\text { Investigar aspectos procedimentais e } \\
\text { conceituais mobilizados por estudantes e por } \\
\text { professores de Matemática em situações- } \\
\text { problema envolvendo o Teorema Fundamental } \\
\text { da Aritmética. }\end{array}$ \\
\hline $\begin{array}{l}\text { Qual a Álgebra a ser } \\
\text { ensinada na formação de } \\
\text { professores que ensinam } \\
\text { Matemática? }\end{array}$ & $2003-2008$ & $\begin{array}{l}\text { Buscar resposta à questão que dá nome ao } \\
\text { projeto por meio da investigação do ensino de } \\
\text { Álgebra nos diferentes níveis educacionais: } \\
\text { infantil, básico, universitário e pós- } \\
\text { universitário. }\end{array}$ \\
\hline $\begin{array}{l}\text { O que se entende por } \\
\text { Álgebra do ponto de vista } \\
\text { curricular e didático? }\end{array}$ & $2003-2009$ & $\begin{array}{l}\text { Investigar o que se entende por Álgebra nos } \\
\text { planos institucional, docente e discente. }\end{array}$ \\
\hline $\begin{array}{l}\text { A Teoria } \\
\text { Números no no Ensino dos } \\
\text { Básico e na Licenciatura }\end{array}$ & $2003-2010$ & $\begin{array}{l}\text { Investigar o estatuto que a Teoria Elementar } \\
\text { dos Números tem nos campos institucional, } \\
\text { docente e discente. }\end{array}$ \\
\hline $\begin{array}{l}\text { O uso de software em } \\
\text { pesquisa qualitativa na }\end{array}$ & $2005-2006$ & $\begin{array}{l}\text { Investigar o uso do software Aplusix (original } \\
\text { em francês) nos processos de ensino e de }\end{array}$ \\
\hline
\end{tabular}




\begin{tabular}{|c|c|c|}
\hline área de Álgebra & & aprendizagem de Álgebra. \\
\hline $\begin{array}{l}\text { Sobre observação e } \\
\text { generalização de padrões: } \\
\text { uma atividade transversal }\end{array}$ & $2005-2010$ & $\begin{array}{l}\text { Investigar o estatuto da observação de } \\
\text { regularidades e generalização de padrões nos } \\
\text { níveis institucional, docente e discente. }\end{array}$ \\
\hline $\begin{array}{l}\text { Concepções acerca de } \\
\text { relações }\end{array}$ & $2006-2009$ & $\begin{array}{l}\text { Investigar concepções de estudantes e } \\
\text { professores de Matemática acerca de relações } \\
\text { algébricas. }\end{array}$ \\
\hline $\begin{array}{l}\text { Expressões, equações e } \\
\text { inequações: pesquisa, } \\
\text { ensino e aprendizagem }\end{array}$ & $2006-2010$ & $\begin{array}{l}\text { Caracterizar o ensino e a aprendizagem de } \\
\text { expressões, equações e inequações no Brasil. }\end{array}$ \\
\hline $\begin{array}{lr}\text { Em busca de situações } \\
\text { propícias para a } \\
\text { aprendizagem } & \text { de } \\
\text { conceitos básicos de } \\
\text { Álgebra Linear }\end{array}$ & $2007-2014$ & $\begin{array}{l}\text { Investigar o ensino e a aprendizagem de } \\
\text { Álgebra Linear em cursos de Ciências Exatas e } \\
\text { afins, tais como: Matemática, Física, Ciência } \\
\text { da Computação, Engenharia, entre outros. etc. }\end{array}$ \\
\hline $\begin{array}{l}\text { A aprendizagem de } \\
\text { Álgebra com a utilização } \\
\text { de } \quad \text { ferramentas } \\
\text { tecnológicas }\end{array}$ & $2008-2013$ & $\begin{array}{l}\text { Investigar, na Educação Algébrica, o papel da } \\
\text { tecnologia e avaliar seu impacto na Educação } \\
\text { Básica, bem como seus efeitos nos campos } \\
\text { institucional, docente e discente. }\end{array}$ \\
\hline $\begin{array}{l}\text { Teoria Elementar dos } \\
\text { Números na Educação } \\
\text { Básica }\end{array}$ & $2010-2011$ & $\begin{array}{l}\text { Investigar o ensino e a aprendizagem de } \\
\text { conceitos da Teoria Elementar do Números na } \\
\text { Educação Básica nos planos curricular, didático } \\
\text { e cognitivo. }\end{array}$ \\
\hline $\begin{array}{l}\text { Contribuições a materiais } \\
\text { de orientação à docência } \\
\text { da Educação Básica }\end{array}$ & $2010-2014$ & $\begin{array}{l}\text { Fornecer contribuições sustentadas em modelos } \\
\text { teóricos acerca da formação e desenvolvimento } \\
\text { do pensamento proporcional e do pensamento } \\
\text { algébrico a materiais de orientação à docência } \\
\text { na Educação Básica. }\end{array}$ \\
\hline $\begin{array}{l}\text { Funções do ponto de vista } \\
\text { cognitivo e didático }\end{array}$ & $2010-2013$ & $\begin{array}{l}\text { Investigar o ensino e a aprendizagem de } \\
\text { funções na Escola Básica. }\end{array}$ \\
\hline 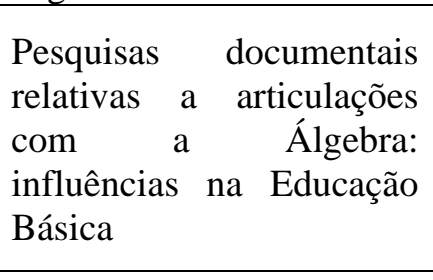 & $2010-2013$ & $\begin{array}{l}\text { Realizar pesquisa documental sobre conteúdos } \\
\text { considerados basilares ao ensino e à } \\
\text { aprendizagem de Álgebra, contemplada em sua } \\
\text { interação com diversos campos intra e } \\
\text { extramatemáticos, que influenciam a Educação } \\
\text { Básica, nos vários segmentos de ensino. }\end{array}$ \\
\hline $\begin{array}{l}\text { Educação Algébrica e o } \\
\text { uso de tecnologias }\end{array}$ & $2010-2014$ & $\begin{array}{l}\text { Investigar os conhecimentos sobre Álgebra por } \\
\text { parte de alunos e professores em formação } \\
\text { inicial e continuada, por simulação, } \\
\text { conhecimentos esses construídos pelos sujeitos } \\
\text { com o auxílio de tecnologias. }\end{array}$ \\
\hline $\begin{array}{l}\text { Álgebra do ponto de vista } \\
\text { epistemológico e didático }\end{array}$ & $2011-2016$ & $\begin{array}{l}\text { Investigar a Álgebra do ponto de vista } \\
\text { epistemológico e didático nos planos } \\
\text { institucional, acadêmico e histórico- } \\
\text { epistemológico por meio de metanálises e } \\
\text { panoramas sobre objetos do saber. }\end{array}$ \\
\hline $\begin{array}{l}\text { Educação Matemática em } \\
\text { cursos de serviço }\end{array}$ & $\begin{array}{l}\text { A partir de } 2014 \\
\text { (em andamento) }\end{array}$ & $\begin{array}{l}\text { Investigar o ensino e a aprendizagem de } \\
\text { tópicos algébricos em cursos de serviço. }\end{array}$ \\
\hline $\begin{array}{l}\text { A Álgebra na Educação } \\
\text { Básica }\end{array}$ & $\begin{array}{l}\text { A partir de } 2014 \\
\text { (em andamento) }\end{array}$ & $\begin{array}{l}\text { Investigar a Álgebra do ponto de vista do } \\
\text { ensino e da aprendizagem no âmbito da } \\
\text { Educação Básica, focalizando concepções e } \\
\text { conhecimentos do aluno e do professor de } \\
\text { Matemática, este tanto em formação inicial } \\
\text { quanto em formação continuada. }\end{array}$ \\
\hline
\end{tabular}


Aportes da Didática à

formação do professor que ensina Matemática

Fonte: elaborado pelos autores com
A partir de 2014 (em andamento)
Investigar, com base no aporte da Didática, questões fundamentais, especialmente aquelas vinculadas à Álgebra, associadas à formação do professor, tanto inicial quanto continuada. compõem ou já compuseram o GPEA.

Por meio do Quadro 1, podemos perceber que os projetos de pesquisa já finalizados e os ainda em andamento são abrangentes, tanto em relação às temáticas, quanto em relação aos níveis de ensino aos quais seus focos estão voltados, da Educação Básica até o pósuniversitário, englobando também reflexões acerca da formação de professores e do ensino e da aprendizagem de Álgebra em cursos nos quais a Matemática está a serviço.

Nos diferentes projetos, são abordados objetos específicos da Álgebra, como relações algébricas, expressões algébricas, equações, inequações, função, Teorema Fundamental da Aritmética e base de um espaço vetorial. Em relação às diferentes subáreas da Álgebra, duas ganham especial destaque nos projetos: Teoria Elementar dos Números e Álgebra Linear.

Existem projetos cujas questões diretrizes, por serem mais abrangentes, têm fundamentado as reflexões estabelecidas no âmbito de outros projetos. Entre tais questões, podemos citar: Qual Álgebra deve ser ensinada na formação do professor de Matemática? O que se entende por Álgebra do ponto de vista curricular e didático? E do ponto de vista epistemológico? E do ponto de vista do ensino e da aprendizagem na Educação Básica? Da mesma forma, para subsidiar outros estudos realizados no Grupo, procedeu-se à investigação, por meio de pesquisas documentais, de conteúdos basilares no ensino e na aprendizagem de Álgebra.

Além disso, buscou-se implementar estudos que pudessem contribuir para o aperfeiçoamento de materiais de orientação à docência na Educação Básica, os quais incluem o Caderno do Professor da Rede Pública Estadual de São Paulo e livros didáticos. A construção de conhecimentos de Álgebra, por parte de alunos e professores, com auxílio de tecnologias, também foi objeto de pesquisas de membros do Grupo, bem como o estatuto de atividade transversal da observação de regularidades e generalização de padrões.

Após esse breve panorama dos projetos de pesquisa já realizados ou em andamento no GPEA, na seção seguinte, tratamos da metodologia empregada na realização do estudo relatado neste artigo. 


\title{
Metodologia
}

Do ponto de vista metodológico, a investigação que originou este artigo abrange preceitos de uma pesquisa caracterizada como mapeamento que, segundo Fiorentini, Passos e Lima (2016, p. 18), diferencia-se da modalidade estado da arte por ter como foco "mais os aspectos descritivos de um campo de estudo do que seus resultados". Nesse sentido, novamente em consonância com as ideias dos autores supracitados,

\begin{abstract}
[...] entendemos o mapeamento da pesquisa como um processo sistemático de levantamento e descrição de informações acerca das pesquisas produzidas sobre um campo específico de estudo, abrangendo um determinado espaço (lugar) e período de tempo. Essas informações dizem respeito aos aspectos físicos dessa produção (descrevendo onde, quando e quantos estudos foram produzidos ao longo do período e quem foram os autores e participantes dessa produção), bem como aos seus aspectos teórico-metodológicos e temáticos (FIORENTINI; PASSOS; LIMA, 2016, p. 18).
\end{abstract}

Respeitando os pressupostos da metodologia empregada, neste artigo, não descrevemos os resultados obtidos nas dissertações e teses desenvolvidas pelos membros do GPEA, mas elementos específicos abordados, quais sejam, conteúdo matemático, objetivo, tipo de produção (dissertação ou tese), nível de ensino, sujeitos (no caso de pesquisas experimentais) e documentos analisados. O corpus inicial da investigação, composto por 111 trabalhos, constituiu-se de 93 dissertações e 18 teses. Destacamos que o número de dissertações é maior que o de teses por conta do funcionamento concomitante, no Programa de Estudos Pós-Graduados em Educação Matemática da PUC-SP, durante alguns anos, do Mestrado Acadêmico e do Mestrado Profissional, e este último atraiu quantidade significativa de professores. As dissertações e teses produzidas pelo GPEA desde sua criação foram orientadas por docentes que são ou já foram membros do Grupo, a saber, Silvia Dias Alcântara Machado, Maria Cristina de Souza Albuquerque Maranhão, Sonia Pitta Coelho, Barbara Lutaif Bianchini, Leila Zardo Puga e Gabriel Loureiro de Lima. Todos os professores têm graduação e mestrado em Matemática; três têm doutorado na mesma área (Silvia, Sonia e Leila), duas, em Psicologia da Educação (Barbara e Maria Cristina), e um, em Educação Matemática (Gabriel). A formação acadêmica desses docentes tem influência direta no fato de as produções do GPEA, na abordagem das temáticas investigadas, caracterizarem-se pelo viés matemático, e não apenas pela perspectiva da área da Educação.

Depois de identificados os trabalhos a serem analisados, o que foi feito por meio dos currículos Lattes dos professores orientadores, acessamos cada uma das dissertações e 
teses selecionadas na biblioteca digital da PUC-SP 5 e elaboramos o Quadro 2, que traz ano de publicação do trabalho, autor, título e objetivo, e o Quadro 3, em que explicitamos o tema ou o conteúdo matemático, o objetivo, o tipo de produção (mestrado ou doutorado), se a pesquisa se caracteriza como experimental ou documental e o nível de ensino no qual a investigação foi realizada. Em relação a este aspecto, ressaltamos que utilizamos a nomenclatura atualmente em vigor no Brasil, a saber: Educação Infantil (alunos de 0 a 5 anos), Ensino Fundamental (subdividido em anos iniciais (do $1^{\circ}$ ao $5^{\circ}$ ano - alunos de 6 a 10 anos) e anos finais (do $6^{\circ}$ ao $9^{\circ}$ ano - alunos de 11 a 14 anos)), Ensino Médio (do $1^{\circ}$ ao $3^{\circ}$ ano - alunos de 15 a 17 anos), Ensino Superior, Pós-Graduação Lato Sensu (especialização) e Pós-Graduação Stricto Sensu (mestrado e doutorado).

Em um primeiro momento, organizamos a análise dos dados considerando o conteúdo matemático enfocado nas dissertações e teses que compunham o corpus inicial. No Quadro 2, apresentamos a relação dos temas ou conteúdos matemáticos contemplados, bem como o número de pesquisas nos quais eles estão presentes.

Por meio dos dados constantes nesse quadro, notamos, em primeiro lugar, a amplitude de temas ou conteúdos matemáticos aos quais os integrantes do GPEA têm direcionado suas investigações. Essa diversidade evidencia que reflexões acerca de questões de Álgebra permeiam as diferentes áreas da Matemática e lhes são fundamentais. Além disso, as informações revelam que os cinco conteúdos matemáticos mais explorados nas pesquisas analisadas são, respectivamente, Números e Operações; Generalização de Padrões; Função; Álgebra Linear e Equações. Dada essa constatação, optamos por analisar detalhadamente as investigações referentes a esses conteúdos.

Quadro 2 - Temas ou conteúdos matemáticos enfocados nas dissertações e teses analisadas
\begin{tabular}{|c|c|c|c|}
\hline Tema ou Conteúdo Matemático & Dissertações & Teses & Total \\
\hline Números e Operações & 19 & 3 & 22 \\
\hline Generalização de Padrões & 11 & 1 & 12 \\
\hline Função & 10 & 0 & 10 \\
\hline Álgebra Linear & 6 & 3 & 9 \\
\hline Equações & 8 & 1 & 9 \\
\hline Inequações e Desigualdades & 7 & 1 & 8 \\
\hline Pensamento Algébrico & 5 & 1 & 6 \\
\hline Razão, Proporção e Pensamento Proporcional & 5 & 0 & 5 \\
\hline Matrizes e Sistemas Lineares & 4 & 0 & 4 \\
\hline Sem conteúdo matemático específico & 3 & 1 & 4 \\
\hline
\end{tabular}

\footnotetext{
5 Todas as dissertações e teses defendidas no Programa de Estudos Pós-Graduados em Educação Matemática da PUC-SP, incluindo as produções do GPEA (para localizá-las, pode-se inserir um filtro de busca considerando-se os nomes dos orientadores), estão disponíveis em <https://sapientia.pucsp.br/> .
} 


\begin{tabular}{|c|c|c|c|}
\hline Geometria Analítica & 1 & 2 & 3 \\
\hline Teoria dos Números & 2 & 1 & 3 \\
\hline Usos da Variável & 3 & 0 & 3 \\
\hline Equações Diofantinas & 3 & 0 & 3 \\
\hline Função, Limite, Derivada e Integral & 0 & 1 & 1 \\
\hline Porcentagem e Regra de Três & 1 & 0 & 1 \\
\hline Educação Algébrica & 0 & 1 & 1 \\
\hline Alfabetização Matemática & 0 & 1 & 1 \\
\hline Sequências Numéricas & 1 & 0 & 1 \\
\hline Produtos Notáveis & 1 & 0 & 1 \\
\hline Distribuição de Probabilidade Exponencial & 1 & 0 & 1 \\
\hline Algoritmos & 0 & 1 & 1 \\
\hline Aritmética & 1 & 0 & 1 \\
\hline Trigonometria & 1 & 0 & 1 \\
\hline TOTAIS & $\mathbf{9 3}$ & $\mathbf{1 8}$ & $\mathbf{1 1 1}$ \\
\hline
\end{tabular}

Fonte: elaborado pelos autores com base em dados da pesquisa.

Ao recortarmos os cinco conteúdos matemáticos mais explorados, o corpus foi reduzido a 62 trabalhos, 54 dissertações e 8 teses. Especificamente no caso dessas produções, destacamos, quando houver, os subtemas tratados em cada um dos conteúdos matemáticos mais abordados, explicitando os números de dissertações e teses referentes a eles e, posteriormente, refinamos nossa análise mediante categorização das pesquisas em experimentais ou documentais; para as da primeira categoria, apresentamos subtema (quando houver), objetivo, tipo de produção (dissertação ou tese) e sujeitos, para as da segunda categoria, apresentamos subtema (quando houver), objetivo, tipo de produção (dissertação ou tese) e documento(s) analisado(s). Passamos, então, à apresentação e à análise dos dados.

\section{Apresentação e Análise dos Dados}

Em primeiro lugar, destacamos, em relação aos cinco temas privilegiados nas pesquisas desenvolvidas no âmbito do GPEA, a predominância no número de dissertações em relação ao número de teses.

Relativamente ao conteúdo Números e Operações, os dados apresentados no Quadro 3 evidenciam, por um lado, a ausência de pesquisas voltadas para o estudo dos números reais e complexos; por outro lado, evidenciam a prevalência dos subtemas Divisibilidade em $\mathbb{N}$ e Números Racionais. No entanto, não foi produzida nenhuma tese a respeito dessas temáticas. Em contrapartida, em relação aos números naturais há apenas teses de doutorado. O subtema Campo Multiplicativo e Conceito de Multiplicação foi o único explorado de maneira equânime em dissertações e teses. 
Notamos como possibilidade para investigações futuras a questão das Tecnologias Digitais de Informação e Comunicação associadas aos processos de ensino e de aprendizagem de Números e Operações, uma vez que apenas duas pesquisas (aquelas relacionadas aos subtemas Números e Tecnologia e Uso de Calculadora e Jogos Matemáticos) estão diretamente vinculadas a esse aspecto.

\begin{tabular}{|c|c|c|c|c|}
\hline $\begin{array}{c}\text { Conteúdo } \\
\text { Matemático }\end{array}$ & Subtema & Dissertações & Teses & Total \\
\hline \multirow{12}{*}{$\begin{array}{l}\text { Números e } \\
\text { Operações }\end{array}$} & Divisibilidade em $\mathbb{N}$ & 5 & 0 & 5 \\
\hline & Números Racionais & 4 & 0 & 4 \\
\hline & Número Zero & 2 & 0 & 2 \\
\hline & Números Naturais & 0 & 2 & 2 \\
\hline & $\begin{array}{c}\text { Campo Multiplicativo e Conceito de } \\
\text { Multiplicação }\end{array}$ & 1 & 1 & 2 \\
\hline & $\begin{array}{c}\text { Operações em } \mathbb{N} \text { com tecnologias não } \\
\text { usuais }\end{array}$ & 1 & 0 & 1 \\
\hline & Números Inteiros & 1 & 0 & 1 \\
\hline & Divisibilidade em $\mathbb{Z}$ & 1 & 0 & 1 \\
\hline & Números e Operações nos PCN & 1 & 0 & 1 \\
\hline & Números e Tecnologia & 1 & 0 & 1 \\
\hline & Sistema de Numeração Decimal & 1 & 0 & 1 \\
\hline & $\begin{array}{c}\text { Uso de Calculadora e Jogos } \\
\text { Matemáticos }\end{array}$ & 1 & 0 & 1 \\
\hline \multicolumn{2}{|r|}{ TOTAIS } & 19 & 3 & 22 \\
\hline
\end{tabular}

Fonte: elaborado pelos autores com base em dados da pesquisa.

Em relação aos estudos de caráter experimental, como ratificam as informações constantes no Quadro 4, a maioria tem como foco os anos finais do Ensino Fundamental. Apenas duas dessas investigações são teses, únicos trabalhos que trazem reflexões acerca do Ensino Superior (com olhar voltado especificamente à formação do pedagogo). Além disso, a ênfase das pesquisas produzidas no âmbito do GPEA está nos números naturais (quatro estudos), em seguida, nos números racionais (três estudos). Os subtemas mais explorados são Divisibilidade em $\mathbb{N}$ (cinco pesquisas) e Números Racionais (quatro pesquisas). Em quatro pesquisas, há discussões relativas ao uso de algum tipo de tecnologia; em uma delas, investiga-se o emprego de tecnologias não usuais no ensino de operações com números naturais, em outra, estuda-se a possível influência de um software específico na aprendizagem de números inteiros por parte de alunos dos anos finais do Ensino Fundamental, na seguinte, analisa-se um projeto (Números em Ação) que envolve o uso de tecnologias desenvolvido pela Rede Pública de Ensino do Estado de São Paulo e, finalmente, há uma investigação em que se considera a utilização de calculadora e de jogos matemáticos como possíveis estratégias 
para refinar a percepção dos alunos em relação aos erros cometidos na manipulação de estruturas aditivas e multiplicativas. Diante do que observamos e considerando o papel desempenhado pelas tecnologias no cenário atual, destacamos a demanda por investigações que tenham como foco o emprego de tecnologias, incluindo jogos digitais educativos, nos processos de ensino e de aprendizagem de números e operações.

Outros apontamentos que podem ser feitos em decorrência dos dados elencados no Quadro 4 são: entre as investigações experimentais, apenas em quatro os professores são sujeitos. Além disso, embora em sala de aula o trabalho com o tema Números e Operações comece nos primeiros anos da trajetória escolar dos estudantes, há somente duas pesquisas direcionadas aos anos iniciais do Ensino Fundamental. A respeito dos objetivos das pesquisas experimentais, notamos a predominância de reflexões acerca das potencialidades de diferentes tecnologias, tanto digitais quanto de outras naturezas, nos processos de ensino e de aprendizagem do tema em questão. Há quantidade significativa de estudos que visam à identificação de conhecimentos mobilizados por estudantes ao trabalharem com determinado aspecto do conteúdo e de investigações nas quais o foco está no diagnóstico de concepções manifestadas pelos alunos em relação a determinado objeto matemático pertinente ao conteúdo em tela.

Quadro 4 - Pesquisas experimentais sobre o conteúdo Números e Operações

\begin{tabular}{|c|c|c|c|c|}
\hline \multicolumn{5}{|c|}{ Conteúdo Matemático: Números e Operações - pesquisas experimentais } \\
\hline Subtema & Objetivo & $\begin{array}{c}\text { Tipo de } \\
\text { Produção }\end{array}$ & $\begin{array}{c}\text { Nível de } \\
\text { Ensino }\end{array}$ & Sujeitos \\
\hline Número Zero & $\begin{array}{l}\text { Investigar } \\
\text { conhecimentos } \\
\text { mobilizados por anais } \\
\text { acerca do valor posicional no } \\
\text { Sistema de Numeração } \\
\text { Decimal e qual o sentido } \\
\text { dado ao número zero nesse } \\
\text { mesmo sistema. }\end{array}$ & Dissertação & $\begin{array}{l}\text { Anos iniciais } \\
\text { do Ensino } \\
\text { Fundamental }\end{array}$ & $\begin{array}{l}\text { Alunos do } 4^{\circ} \\
\text { ano }\end{array}$ \\
\hline $\begin{array}{l}\text { Números } \\
\text { Naturais }\end{array}$ & $\begin{array}{l}\text { Verificar se } r \\
\text { conhecimentos acerca dos } \\
\text { números naturais que alunos } \\
\text { do curso de Pedagogia, } \\
\text { também docentes na } \\
\text { Educação Infantil ou nos } \\
\text { anos iniciais do Ensino } \\
\text { Fundamental, construíram } \\
\text { quando cursaram a disciplina } \\
\text { que trata dos conteúdos de } \\
\text { Matemática ampliaram seus } \\
\text { saberes matemáticos e deram } \\
\text { novo significado às suas } \\
\text { práticas docentes. }\end{array}$ & Tese & $\begin{array}{l}\text { Ensino } \\
\text { Superior }\end{array}$ & $\begin{array}{c}\text { Professores } \\
\text { universitários } \\
\text { de cursos de } \\
\text { Pedagogia e } \\
\text { alunos desses } \\
\text { cursos (já } \\
\text { atuantes como } \\
\text { docentes) que } \\
\text { também foram } \\
\text { observados } \\
\text { nas escolas em } \\
\text { que } \\
\text { lecionavam }\end{array}$ \\
\hline
\end{tabular}




\begin{tabular}{|c|c|c|c|c|}
\hline \multirow{5}{*}{$\begin{array}{l}\text { Divisibilidade } \\
\text { em } \mathbb{N}\end{array}$} & $\begin{array}{l}\text { Diagnosticar as concepções } \\
\text { de alunos sobre a divisão de } \\
\text { números naturais. }\end{array}$ & Dissertação & $\begin{array}{l}\text { Anos finais } \\
\text { do Ensino } \\
\text { Fundamental } \\
\end{array}$ & $\begin{array}{c}\text { Alunos do } 7^{\circ} \\
\text { ano }\end{array}$ \\
\hline & $\begin{array}{l}\text { Investigar a concepção de } \\
\text { alunos sobre divisibilidade } \\
\text { dos números naturais. }\end{array}$ & Dissertação & $\begin{array}{l}\text { Ensino } \\
\text { Médio }\end{array}$ & $\begin{array}{l}\text { Alunos do } 1^{\circ} \\
\quad \text { ano }\end{array}$ \\
\hline & $\begin{array}{l}\text { Investigar a concepção de } \\
\text { alunos sobre divisibilidade } \\
\text { por meio de uma abordagem } \\
\text { com calculadora. }\end{array}$ & Dissertação & $\begin{array}{l}\text { Anos finais } \\
\text { do Ensino } \\
\text { Fundamental }\end{array}$ & $\begin{array}{c}\text { Alunos do } 6^{\circ} \\
\text { ano }\end{array}$ \\
\hline & $\begin{array}{l}\text { Investigar o efeito da } \\
\text { retomada da divisibilidade } \\
\text { dos números naturais na } \\
\text { compreensão do estudante } \\
\text { sobre a divisibilidade de } \\
\text { polinômios. }\end{array}$ & Dissertação & $\begin{array}{l}\text { Ensino } \\
\text { Médio }\end{array}$ & $\begin{array}{c}\text { Alunos do } \\
\text { Ensino Médio }\end{array}$ \\
\hline & $\begin{array}{l}\text { Investigar como alunos } \\
\text { mobilizam conhecimentos a } \\
\text { respeito de divisibilidade de } \\
\text { números naturais }\end{array}$ & Dissertação & $\begin{array}{l}\text { Anos finais } \\
\text { do Ensino } \\
\text { Fundamental }\end{array}$ & $\begin{array}{c}\text { Alunos do } 6^{\circ} \\
\text { ano }\end{array}$ \\
\hline $\begin{array}{l}\text { Operações em } \\
\mathbb{N} \text { com } \\
\text { tecnologias } \\
\text { não usuais }\end{array}$ & $\begin{array}{l}\text { Investigar se e como alunos } \\
\text { que apresentam dificuldades } \\
\text { na resolução de atividades } \\
\text { que envolvem operações com } \\
\text { números naturais } \\
\text { aprofundam reus } \\
\text { conhecimentos quando lhes é } \\
\text { dada a oportunidade do uso } \\
\text { de tecnologias não usuais em } \\
\text { sala de aula. }\end{array}$ & Dissertação & $\begin{array}{l}\text { Anos finais } \\
\text { do Ensino } \\
\text { Fundamental }\end{array}$ & $\begin{array}{c}\text { Alunos do } 8^{\circ} \\
\text { ano }\end{array}$ \\
\hline $\begin{array}{l}\text { Números } \\
\text { Inteiros }\end{array}$ & $\begin{array}{l}\text { Investigar como o uso do } \\
\text { software APLUSIX influi na } \\
\text { aprendizagem de números } \\
\text { inteiros. }\end{array}$ & Dissertação & $\begin{array}{l}\text { Anos finais } \\
\text { do Ensino } \\
\text { Fundamental }\end{array}$ & $\begin{array}{c}\text { Alunos do } 7^{\circ} \\
\text { ano }\end{array}$ \\
\hline \multirow{3}{*}{$\begin{array}{l}\text { Números } \\
\text { Racionais }\end{array}$} & $\begin{array}{l}\text { Investigar se alunos atribuem } \\
\text { sentido restrito às relações } \\
\text { chegar antes de e não chegar } \\
\text { depois de e, caso o façam, se } \\
\text { esses significados podem ser } \\
\text { ampliados como resultado de } \\
\text { um processo de intervenção } \\
\text { didática. }\end{array}$ & Dissertação & $\begin{array}{l}\text { Ensino } \\
\text { Médio }\end{array}$ & $\begin{array}{l}\text { Alunos do } 1^{\circ} \\
\text { ano }\end{array}$ \\
\hline & $\begin{array}{l}\text { Investigar quais conceitos, } \\
\text { propriedades } \\
\text { procedimentos matemáticos, } \\
\text { bem como quais domínios } \\
\text { (em termos de representação } \\
\text { numérica, gráfica e outras) } \\
\text { são utilizados por estudantes } \\
\text { na resolução de atividades } \\
\text { abrangendo o enquadramento } \\
\text { de números racionais em } \\
\text { intervalos de racionais. }\end{array}$ & Dissertação & $\begin{array}{l}\text { Anos finais } \\
\text { do Ensino } \\
\text { Fundamental }\end{array}$ & $\begin{array}{l}\text { Alunos do } 8^{\circ} \\
\text { ano }\end{array}$ \\
\hline & Investigar o que professores & Dissertação & Anos finais & Professores do \\
\hline
\end{tabular}




\begin{tabular}{|c|c|c|c|c|}
\hline & $\begin{array}{l}\text { consideram ao elaborar aulas } \\
\text { referentes a atividades que } \\
\text { envolvem enquadramento de } \\
\text { números racionais em } \\
\text { intervalos. }\end{array}$ & & $\begin{array}{c}\text { do Ensino } \\
\text { Fundamental }\end{array}$ & $8^{\circ}$ e do $9^{\circ}$ ano \\
\hline & $\begin{array}{l}\text { Investigar a compreensão de } \\
\text { alunos sobre a divisão de } \\
\text { números racionais na forma } \\
\text { decimal. }\end{array}$ & Dissertação & $\begin{array}{l}\text { Anos finais } \\
\text { do Ensino } \\
\text { Fundamental }\end{array}$ & $\begin{array}{c}\text { Alunos do } 7^{\circ} \\
\text { ano }\end{array}$ \\
\hline $\begin{array}{l}\text { Números e } \\
\text { Tecnologia }\end{array}$ & $\begin{array}{l}\text { Analisar o uso da sala de } \\
\text { informática e as novas } \\
\text { tecnologias presentes no } \\
\text { projeto Números em Ação, da } \\
\text { Rede Estadual Paulista, } \\
\text { como suporte para alunos } \\
\text { com problemas de } \\
\text { aprendizagem na disciplina } \\
\text { de matemática. }\end{array}$ & Dissertação & $\begin{array}{l}\text { Anos finais } \\
\text { do Ensino } \\
\text { Fundamental }\end{array}$ & $\begin{array}{c}\text { Professores e } \\
\text { alunos de } 6^{\circ} \mathrm{e} \\
7^{\circ} \text { ano }\end{array}$ \\
\hline $\begin{array}{l}\text { Campo } \\
\text { Multiplicativo } \\
\text { e Conceito de } \\
\text { Multiplicação }\end{array}$ & $\begin{array}{l}\text { Investigar a constituição de } \\
\text { saberes da docência no } \\
\text { campo multiplicativo ao } \\
\text { longo da formação inicial e } \\
\text { continuada do licenciado em } \\
\text { Pedagogia e no âmbito das } \\
\text { produções de seus alunos. }\end{array}$ & Tese & $\begin{array}{c}\text { Ensino } \\
\text { Superior e } \\
\text { Anos iniciais } \\
\text { do Ensino } \\
\text { Fundamental }\end{array}$ & $\begin{array}{l}\text { Professores } \\
\text { pedagogos e } \\
\text { seus alunos }\end{array}$ \\
\hline $\begin{array}{l}\text { Uso de } \\
\text { Calculadora e } \\
\text { de Jogos } \\
\text { Matemáticos }\end{array}$ & $\begin{array}{l}\text { Investigar quais estratégias } \\
\text { pedagógicas, considerando o } \\
\text { uso da calculadora em sala } \\
\text { de aula, podem refinar a } \\
\text { percepção dos erros } \\
\text { cometidos por alunos na } \\
\text { manipulação de estruturas } \\
\text { aditivas e multiplicativas. }\end{array}$ & Dissertação & $\begin{array}{l}\text { Anos finais } \\
\text { do Ensino } \\
\text { Fundamental }\end{array}$ & $\begin{array}{c}\text { Alunos do } 7^{\circ} \\
\text { ano }\end{array}$ \\
\hline
\end{tabular}

Fonte: elaborado pelos autores com base em dados da pesquisa.

A respeito dos estudos documentais relativos ao conteúdo Números e Operações, por meio do Quadro 5, notamos a predominância de investigações de mestrado, havendo apenas uma tese. O nível de ensino privilegiado é o Fundamental (quatro pesquisas); em um estudo de doutorado, o nível de ensino contemplado é Especialização. Uma ampla gama de materiais foi alvo de análise dos pesquisadores do GPEA que se dedicaram a essa temática: livros de história da Matemática, artigos, dissertações, teses, coleções de livros didáticos, documentos oficiais (Parâmetros Curriculares Nacionais), livros publicados pela Secretaria Municipal de Educação de uma cidade de Minas Gerais e videoaulas. A opção por um ou outro material está, obviamente, vinculada aos objetivos das pesquisas que, também como evidenciam as informações apresentadas no Quadro 5, são diversos, mas, em alguma medida, na maior parte dos estudos, estão relacionados ao 
interesse de compreender a abordagem de determinado conceito proposta em livros didáticos, documentos oficiais ou materiais de outras naturezas.

Quadro 5: Pesquisas documentais sobre o conteúdo Números e Operações

\begin{tabular}{|c|c|c|c|c|}
\hline \multicolumn{5}{|c|}{ Conteúdo Matemático: Números e Operações - pesquisas documentais } \\
\hline Subtema & Objetivo & $\begin{array}{c}\text { Tipo de } \\
\text { Produção }\end{array}$ & $\begin{array}{c}\text { Nível de } \\
\text { Ensino }\end{array}$ & $\begin{array}{c}\text { Documentos } \\
\text { Analisados } \\
\end{array}$ \\
\hline Número Zero & $\begin{array}{l}\text { Investigar as dificuldades } \\
\text { que surgiram ao longo da } \\
\text { história para se considerar o } \\
\text { zero como número. }\end{array}$ & Dissertação & Não há & $\begin{array}{c}\text { Livros de } \\
\text { História da } \\
\text { Matemática, } \\
\text { artigos e uma } \\
\text { dissertação }\end{array}$ \\
\hline $\begin{array}{l}\text { Números } \\
\text { Naturais }\end{array}$ & $\begin{array}{lr}\text { Investigar } & \text { conhecimentos } \\
\text { relativos ao número natural } \\
\text { construídos por professoras- } \\
\text { alunas na disciplina } \\
\text { Construção } \\
\text { Conhecimento do } \\
\text { Matemático, de um curso de } \\
\text { especialização } \\
\text { semipresencial intitulado } \\
\text { Psicopedagogia com foco em } \\
\text { sala de aula. }\end{array}$ & Tese & Especialização & $\begin{array}{l}\text { Ementário, } \\
\text { videoaulas, } \\
\text { livros e } \\
\text { respostas das } \\
\text { professoras- } \\
\text { alunas }\end{array}$ \\
\hline $\begin{array}{c}\text { Divisibilidade } \\
\text { em } \mathbb{Z}\end{array}$ & $\begin{array}{llr}\text { Verificar a abordagem } & \text { de } \\
\text { números inteiros, } & \text { em } \\
\text { particular o conceito } & \text { de } \\
\text { divisibilidade. } & & \\
\end{array}$ & Dissertação & $\begin{array}{c}\text { Ensino } \\
\text { Fundamental }\end{array}$ & $\begin{array}{c}\text { Três } \\
\text { coleções de } \\
\text { livros } \\
\text { didáticos }\end{array}$ \\
\hline $\begin{array}{l}\text { Números e } \\
\text { Operações nos } \\
\text { PCN }\end{array}$ & $\begin{array}{l}\text { Investigar a abordagem } \\
\text { proposta para números e } \\
\text { operações. }\end{array}$ & Dissertação & $\begin{array}{c}\text { Ensino } \\
\text { Fundamental }\end{array}$ & $\begin{array}{c}\text { Parâmetros } \\
\text { Curriculares } \\
\text { Nacionais de } \\
1997 \\
\end{array}$ \\
\hline $\begin{array}{l}\text { Sistema de } \\
\text { Numeração } \\
\text { Decimal }\end{array}$ & $\begin{array}{l}\text { Investigar a docência dos } \\
\text { anos iniciais e a } \\
\text { compreensão do sistema de } \\
\text { numeração decimal. }\end{array}$ & Dissertação & $\begin{array}{c}\text { Ensino } \\
\text { Fundamental }\end{array}$ & $\begin{array}{c}\text { Dissertações } \\
\text { e teses }\end{array}$ \\
\hline $\begin{array}{l}\text { Campo } \\
\text { Multiplicativo } \\
\text { e Conceito de } \\
\text { Multiplicaçãao }\end{array}$ & $\begin{array}{l}\text { Investigar o processo } \\
\text { elaboração do conceito de } \\
\text { multiplicação do } 1^{\circ} \text { ao } 5^{\circ} \\
\text { ano. }\end{array}$ & Dissertação & $\begin{array}{c}\text { Ensino } \\
\text { Fundamental }\end{array}$ & $\begin{array}{l}\text { Livros da } \\
\text { Coleção do } \\
\text { Professor } \\
\text { adotados na } \\
\text { Rede } \\
\text { Municipal de } \\
\text { Ensino de } \\
\text { uma cidade } \\
\text { de Minas } \\
\text { Gerais }\end{array}$ \\
\hline
\end{tabular}

Fonte: elaborado pelos autores com base em dados da pesquisa.

Em relação ao Quadro 6, os dados evidenciam um número elevado de pesquisas, 12 no total, sobre Generalização de Padrões, o que se justifica pelo desenvolvimento, no âmbito do Grupo, entre 2005 e 2010, de um projeto de pesquisa intitulado Sobre Observação e Generalização de Padrões: uma atividade transversal. Além disso, uma 
vez que generalizar padrões é uma atividade essencial para o desenvolvimento do pensamento algébrico, mesmo após o término do mencionado projeto, outras pesquisas sobre essa temática foram produzidas. Convém destacar que, ao contrário do observado no tocante a outros conteúdos matemáticos, nas pesquisas relativas a Generalização de Padrões, não identificamos subtemas. A particularidade, como podemos observar com base nos dados do Quadro 7, é que quatro das investigações relativas à temática articulam generalização de padrões com sequências numéricas, em especial progressões aritméticas e geométricas.

Quadro 6 - Dissertações e teses sobre o conteúdo Generalização de Padrões

\begin{tabular}{|c|c|c|c|}
\hline Conteúdo Matemático & Dissertações & Teses & Pesquisas \\
\hline Generalização de Padrões & 11 & 1 & 12 \\
\hline TOTAIS & $\mathbf{1 1}$ & $\mathbf{1}$ & $\mathbf{1 2}$ \\
\hline
\end{tabular}

Fonte: elaborado pelos autores com base em dados da pesquisa.

Os dados apresentados no Quadro 7 evidenciam que entre as pesquisas experimentais sobre Generalização de Padrões, há somente investigações de mestrado. Embora esse conteúdo, em virtude de sua importância para o desenvolvimento do pensamento algébrico, deva ser trabalhado desde os primeiros anos da trajetória escolar, predomina, no corpus analisado, estudos voltados ao Ensino Médio (cinco pesquisas), além do que, há, em menor número, investigações relativas aos anos finais (duas) e aos anos iniciais do Ensino Fundamental (uma) e, ainda, uma pesquisa na qual o nível de ensino não é explicitado. Salientamos a ausência de investigações voltadas ao Ensino Superior, especialmente aos cursos de Licenciatura em Matemática.

Observamos a prevalência de trabalhos em que alunos são os sujeitos de pesquisa: do Ensino Médio (cinco pesquisas) e dos anos finais do Ensino Fundamental (uma pesquisa). Os professores estão presentes como sujeitos em quatro investigações; são docentes dos anos finais do Ensino Fundamental (uma pesquisa), do Ensino Fundamental na Rede Estadual de Ensino de São Paulo (uma pesquisa), docentes que participaram de curso de formação continuada oferecido pela Rede Municipal de Ensino de São Paulo (uma pesquisa) e docentes das oficinas Experiências Matemáticas das Escolas de Tempo Integral (uma pesquisa).

Em quatro das dez pesquisas experimentais, o conteúdo Generalização de Padrões é trabalhado de maneira articulada com as sequências numéricas; em três trabalhos, o foco recai sobre progressões aritméticas (duas pesquisas) e geométricas (uma pesquisa). Em relação aos objetivos dos estudos, cinco estão relacionados a compreender como os alunos trabalham com situações que envolvem generalização de padrões; três, aos 
conhecimentos ou percepções de professores a respeito de atividades que envolvem o conteúdo em questão e a como explorá-lo em sala de aula; um; às condições a serem criadas para que os alunos desenvolvam generalizações, e um, a como o conteúdo é explorado em oficinas realizadas em escolas de tempo integral.

Quadro 7 - Pesquisas experimentais sobre o conteúdo Generalização de Padrões

\begin{tabular}{|c|c|c|c|}
\hline \multicolumn{4}{|c|}{ Conteúdo Matemático: Generalização de Padrões - pesquisas experimentais } \\
\hline Objetivo & $\begin{array}{c}\text { Tipo de } \\
\text { Produção }\end{array}$ & $\begin{array}{l}\text { Nível de } \\
\text { Ensino }\end{array}$ & Sujeitos \\
\hline $\begin{array}{l}\text { Investigar o conhecimento que } \\
\text { os professores de Matemática } \\
\text { apresentam sobre o estudo de } \\
\text { generalizações de padrões e } \\
\text { regularidades. }\end{array}$ & Dissertação & $\begin{array}{l}\text { Anos finais } \\
\text { do Ensino } \\
\text { Fundamental }\end{array}$ & Professores de $8^{\circ}$ ano \\
\hline $\begin{array}{l}\text { Investigar se e como alunos } \\
\text { resolvem situações-problema } \\
\text { que envolvem generalização de } \\
\text { padrões. }\end{array}$ & Dissertação & $\begin{array}{l}\text { Ensino } \\
\text { Médio }\end{array}$ & Alunos do $1^{\circ}, 2^{\circ}$ e $3^{\circ}$ ano \\
\hline $\begin{array}{l}\text { Verificar se professores } \\
\text { trabalham com atividades que } \\
\text { envolvem a observação de } \\
\text { regularidades e de generalização } \\
\text { de padrão, e, caso o façam, } \\
\text { quais estratégias de resolução } \\
\text { preveem que seus alunos } \\
\text { utilizem. }\end{array}$ & Dissertação & $\begin{array}{c}\text { Ensino } \\
\text { Fundamental }\end{array}$ & $\begin{array}{l}\text { Professores da Rede Estadual } \\
\text { de Ensino de São Paulo }\end{array}$ \\
\hline $\begin{array}{l}\text { Investigar se e como alunos } \\
\text { criam estratégias para resolver } \\
\text { situações que envolvem a } \\
\text { percepção e generalização de } \\
\text { padrões em sequências. }\end{array}$ & Dissertação & $\begin{array}{l}\text { Anos finais } \\
\text { do Ensino } \\
\text { Fundamental }\end{array}$ & Alunos do $6^{\circ}$ ano \\
\hline $\begin{array}{l}\text { Investigar quais são as } \\
\text { mudanças de percepção dos } \\
\text { professores sobre o tema } \\
\text { observação e generalização de } \\
\text { padrões ao vivenciarem um } \\
\text { processo de pesquisa em sua } \\
\text { própria sala de aula. }\end{array}$ & Dissertação & $\begin{array}{c}\text { Ensino } \\
\text { Fundamental }\end{array}$ & $\begin{array}{c}\text { Professoras que participaram } \\
\text { de curso de formação } \\
\text { continuada proposto pelo } \\
\text { Projeto de Valorização do } \\
\text { Educador e Melhoria da } \\
\text { Qualidade de Ensino da Rede } \\
\text { Municipal de Ensino de São } \\
\text { Paulo } \\
\end{array}$ \\
\hline $\begin{array}{l}\text { Investigar como o aluno } \\
\text { observa, realiza e compreende } \\
\text { as atividades de observação de } \\
\text { regularidades e de generalização } \\
\text { de padrões. }\end{array}$ & Dissertação & $\begin{array}{l}\text { Ensino } \\
\text { Médio }\end{array}$ & Aluno que terminou o $1^{\circ}$ ano \\
\hline $\begin{array}{l}\text { Verificar como atividades que } \\
\text { envolvem observação e } \\
\text { generalização de padrões são } \\
\text { exploradas nas oficinas } \\
\text { Experiências Matemáticas das } \\
\text { escolas de tempo integral. }\end{array}$ & Dissertação & $\begin{array}{l}\text { Não é } \\
\text { explicitado }\end{array}$ & $\begin{array}{c}\text { Cinco professores das } \\
\text { oficinas Experiências } \\
\text { Matemáticas }\end{array}$ \\
\hline $\begin{array}{l}\text { Investigar se é possível criar } \\
\text { condições para que alunos }\end{array}$ & Dissertação & $\begin{array}{l}\text { Ensino } \\
\text { Médio }\end{array}$ & Alunos do $1^{\circ}$ ano \\
\hline
\end{tabular}




\begin{tabular}{|c|c|c|c|}
\hline $\begin{array}{l}\text { generalizem } \text { termos de } \\
\text { progressões aritméticas e, se o } \\
\text { fazem, se a generalização } \\
\text { permite que construam uma } \\
\text { fórmula para o termo geral desse } \\
\text { tipo de sequência. }\end{array}$ & & & \\
\hline $\begin{array}{l}\text { Investigar se e como estudantes } \\
\text { observam regularidades e as } \\
\text { generalizam, construindo } \\
\text { expressões relativas às } \\
\text { progressões geométricas com o } \\
\text { apoio de calculadora simples ou } \\
\text { de impressora. }\end{array}$ & Dissertação & $\begin{array}{l}\text { Ensino } \\
\text { Médio }\end{array}$ & Alunos do $1^{\circ}$ ano \\
\hline $\begin{array}{l}\text { Investigar se alunos, diante de } \\
\text { atividades de observação e } \\
\text { generalização de padrões de } \\
\text { sequências, constroem uma } \\
\text { fórmula para o termo genérico } \\
\text { de uma Progressão Aritmética. }\end{array}$ & Dissertação & $\begin{array}{l}\text { Ensino } \\
\text { Médio }\end{array}$ & Alunos do $2^{\circ}$ ano \\
\hline
\end{tabular}

Fonte: elaborado pelos autores com base em dados da pesquisa.

No Quadro 8, observamos que apenas duas investigações documentais sobre Generalização de Padrões foram desenvolvidas: uma dissertação e uma tese. $\mathrm{Na}$ primeira, analisam-se livros didáticos selecionados pelo Programa Nacional do Livro Didático (PNLD) em 2011, com foco nos anos finais do Ensino Fundamental; na segunda, examinam-se as contribuições de pesquisas brasileiras sobre o tema, sem se voltar a um nível de ensino específico. Além de certamente haver demanda por outras investigações de cunho documental sobre generalização de padrões, em razão da importância do trabalho com esse conteúdo para o desenvolvimento do pensamento algébrico, notamos lacunas em relação ao tipo de material passível de ser pesquisado, como notas de aula, documentos oficiais, entre outros. Como possíveis objetos de estudo, temos a generalização de padrões com o uso de recursos tecnológicos, por exemplo, calculadora e softwares educativos, e questões relacionadas a esse conteúdo presentes no Ensino Superior.

Quadro 8 - Pesquisas documentais sobre o conteúdo Generalização de Padrões

\begin{tabular}{|c|c|c|c|}
\hline \multicolumn{4}{|c|}{ Conteúdo Matemático: Generalização de Padrões - pesquisas documentais } \\
\hline Objetivo & $\begin{array}{l}\text { Tipo de } \\
\text { Produção }\end{array}$ & $\begin{array}{c}\text { Nível de } \\
\text { Ensino }\end{array}$ & Documentos Analisados \\
\hline $\begin{array}{l}\text { Analisar se a linguagem } \\
\text { algébrica é introduzida por meio } \\
\text { de atividades de generalização } \\
\text { de padrões e como isso ocorre. }\end{array}$ & Dissertação & $\begin{array}{l}\text { Anos finais } \\
\text { do Ensino } \\
\text { Fundamental }\end{array}$ & $\begin{array}{c}\text { Livros didáticos selecionados } \\
\text { no PNLD/2011 }\end{array}$ \\
\hline  & Tese & Não há & Teses e dissertações \\
\hline
\end{tabular}


sobre o tema generalização de

padrões matemáticos.

Fonte: elaborado pelos autores com base em dados da pesquisa.

Em relação ao tema Função, como podemos perceber com base nos dados constantes no Quadro 9, foram realizadas apenas investigações de mestrado. Não foram foco de atenção as funções cosseno, tangente, cotangente, secante, cossecante e as respectivas funções inversas, além de funções definidas por várias sentenças matemáticas, o que indica possibilidade de pesquisas futuras no âmbito do Grupo. O predomínio é de pesquisas relacionadas ao conceito de função (três estudos) e à função exponencial (dois estudos). Dada a importância da ideia de função para a Modelagem Matemática, chama a atenção o fato de haver, entre os trabalhos analisados, apenas um que articula esses dois aspectos. Em relação aos diferentes tipos de funções, nos estudos do GPEA, já foram contemplados logarítmica, exponencial, modular e seno. Entendemos como relevante o desenvolvimento de investigações relacionadas à aplicação do conceito de função a outras áreas do conhecimento, como Física, Química, Engenharias, Economia, Administração e Computação.

Quadro 9 - Dissertações e teses sobre o conteúdo Função

\begin{tabular}{|c|c|c|c|c|}
\hline $\begin{array}{c}\text { Conteúdo } \\
\text { Matemático }\end{array}$ & Subtema & Dissertações & Teses & Total \\
\hline \multirow{4}{*}{ Função } & Conceito de Função & 3 & 0 & 3 \\
\cline { 2 - 5 } & Função Exponencial & 2 & 0 & 2 \\
\cline { 2 - 5 } & Função e Modelagem Matemática & 1 & 0 & 1 \\
\cline { 2 - 5 } & Relações Funcionais em Diferentes & 1 & 0 & 1 \\
\cline { 2 - 5 } & Representações & 1 & 0 & 1 \\
\cline { 2 - 5 } & Função Logarítmica & 1 & 0 & 1 \\
\cline { 2 - 5 } & Função Seno & 1 & 0 & 1 \\
\hline & Função Modular & $\mathbf{1 0}$ & $\mathbf{0}$ & $\mathbf{1 0}$ \\
\hline
\end{tabular}

Fonte: elaborado pelos autores com base em dados da pesquisa.

Por meio do Quadro 10, podemos perceber que, em relação às pesquisas experimentais sobre o conteúdo Função, o foco é o Ensino Médio (quatro pesquisas); há apenas uma investigação voltada aos anos finais do Ensino Fundamental. Identificamos, assim, uma lacuna nas produções do GPEA em relação a investigações experimentais relacionadas ao conteúdo função no Ensino Superior. Nas pesquisas analisadas, os alunos, especificamente do Ensino Médio (três estudos) e dos anos finais do Ensino Fundamental (um estudo), predominam como sujeitos; há apenas uma investigação em que professores são sujeitos, o que revela ser mais uma possibilidade de estudo futuro. 
Os tipos de função abordados nos trabalhos são os seguintes: logarítmica, exponencial, seno e modular. Há lacunas referentes a outros tipos de função, como já destacamos ao comentar o Quadro 9. Em relação aos objetivos, em três das seis pesquisas ganham destaque as diferentes representações semióticas para o objeto matemático Função e um dos estudos considera a utilização do software GeoGebra. O uso de tecnologias está presente em outro estudo, que envolve o software Winplot. Notamos que em três das seis pesquisas mencionadas no Quadro 10 os objetivos estão relacionados à compreensão dos efeitos, na aprendizagem dos estudantes, de sequências didáticas implementadas em sala de aula. Em uma das investigações, objetiva-se refletir como a compreensão das relações funcionais em suas diferentes representações podem contribuir para a introdução do pensamento algébrico e da linguagem da Álgebra. Salientamos, ainda, que há demanda para a realização de investigações que enfoquem no uso de tecnologias digitais, como, por exemplo, computadores e smartphones.

Quadro 10 - Pesquisas experimentais sobre o conteúdo Função

\begin{tabular}{|c|c|c|c|c|}
\hline \multicolumn{5}{|c|}{ Conteúdo Matemático: Função - pesquisas experimentais } \\
\hline Subtema & Objetivo & $\begin{array}{c}\text { Tipo de } \\
\text { Produção }\end{array}$ & $\begin{array}{l}\text { Nível de } \\
\text { Ensino }\end{array}$ & Sujeitos \\
\hline $\begin{array}{l}\text { Relações } \\
\text { Funcionais em } \\
\text { Diferentes } \\
\text { Representações }\end{array}$ & $\begin{array}{l}\text { Investigar } \text { como as } \\
\text { relações funcionais em } \\
\text { diferentes representações } \\
\text { contribuem para a } \\
\text { introdução ao pensamento } \\
\text { e à linguagem da Álgebra. }\end{array}$ & Dissertação & $\begin{array}{lr}\text { Anos } & \text { finais } \\
\text { do } & \text { Ensino } \\
\text { Fundamental }\end{array}$ & $\begin{array}{l}\text { Alunos do } 7^{\circ} \\
\text { ano }\end{array}$ \\
\hline $\begin{array}{l}\text { Função } \\
\text { Logarítmica }\end{array}$ & $\begin{array}{l}\text { Investigar o efeito de uma } \\
\text { sequência didática sobre } \\
\text { funções logarítmicas } \\
\text { elaborada com o intuito } \\
\text { de possibilitar que o aluno } \\
\text { explore as representações } \\
\text { com o software } \\
\text { GeoGebra. }\end{array}$ & Dissertação & $\begin{array}{l}\text { Ensino } \\
\text { Médio }\end{array}$ & $\begin{array}{l}\text { Alunos do } 3^{\circ} \\
\text { ano }\end{array}$ \\
\hline $\begin{array}{l}\text { Função } \\
\text { Exponencial }\end{array}$ & $\begin{array}{l}\text { Analisar se as atividades } \\
\text { apresentadas no Caderno } \\
\text { do Professor contribuem } \\
\text { ou não para a } \\
\text { compreensão do aluno a } \\
\text { respeito do objeto Função } \\
\text { Exponencial, e se os } \\
\text { alunos conseguem realizar } \\
\text { ou não as mudanças de } \\
\text { representação semiótica à } \\
\text { luz da teoria de Duval. }\end{array}$ & Dissertação & $\begin{array}{l}\text { Ensino } \\
\text { Médio }\end{array}$ & $\begin{array}{l}\text { Alunos do } 2^{\circ} \\
\text { ano }\end{array}$ \\
\hline Função Seno & $\begin{array}{l}\text { Investigar } \text { se uma } \\
\text { sequência de atividades } \\
\text { no contexto físico- }\end{array}$ & Dissertação & $\begin{array}{l}\text { Ensino } \\
\text { Médio }\end{array}$ & $\begin{array}{l}\text { Alunos do } 2^{\circ} \\
\text { ano }\end{array}$ \\
\hline
\end{tabular}




\begin{tabular}{|l|l|l|l|l|}
\hline & $\begin{array}{l}\text { matemático, com o uso do } \\
\text { software Winplot, } \\
\text { promove a aprendizagem } \\
\text { de alunos a respeito da } \\
\text { Função Seno. }\end{array}$ & & \\
\hline Função Modular & $\begin{array}{l}\text { Investigar contribuições } \\
\text { do ensino da Função } \\
\text { Modular para a Eduçaço } \\
\text { Básica. }\end{array}$ & Dissertação & $\begin{array}{l}\text { Ensino } \\
\text { Médio }\end{array}$ & $\begin{array}{c}\text { Professores do } \\
\text { Ensino Médio } \\
\text { também } \\
\text { estudantes de } \\
\text { pós-graduação } \\
\text { em Educação } \\
\text { Matemática }\end{array}$ \\
\hline
\end{tabular}

Fonte: elaborado pelos autores com base em dados da pesquisa.

O conteúdo do Quadro 11 permite-nos notar que, em termos de pesquisas documentais sobre Função, em relação ao nível de ensino, uma pesquisa refere-se aos anos finais do Ensino Fundamental, três estudos referem-se simultaneamente aos anos finais do Ensino Fundamental e ao Ensino Médio, e uma refere-se ao Ensino Médio. Assim como observado na esfera das pesquisas experimentais, não há investigações voltadas ao Ensino Superior. Diferentes tipos de materiais foram contemplados nas análises: materiais de ensino da Rede Pública de Ensino do Estado de São Paulo, livros didáticos, artigos publicados na revista Educação Matemática Pesquisa e dissertações de mestrado. Não encontramos análises de livros de História da Matemática, de materiais preparados pelo professor para ministrar aulas, de documentos oficiais, de ementas e planos de ensino, do currículo, entre outros elementos passíveis de serem analisados. Em relação aos subtemas, há predominância de discussões acerca do conceito de Função. Se voltarmos nossa atenção a tipos específicos de funções, nas pesquisas experimentais em tela, são abordadas apenas as exponenciais. Considerando os objetivos de pesquisa, a maior parte (três) dos estudos destina-se a analisar como são abordadas as funções em livros e em outros tipos de materiais didáticos, duas pesquisas voltam-se às contribuições de outras investigações para reflexões a respeito do tema, uma delas está relacionada à Modelagem Matemática.

Quadro 11 - Pesquisas documentais sobre o conteúdo Função

\begin{tabular}{|c|c|c|c|c|}
\hline \multicolumn{5}{|c|}{ Conteúdo Matemático: Função - pesquisas documentais } \\
\hline Subtema & Objetivo & $\begin{array}{c}\text { Tipo de } \\
\text { Produção }\end{array}$ & $\begin{array}{l}\text { Nível de } \\
\text { Ensino }\end{array}$ & $\begin{array}{l}\text { Documentos } \\
\text { Analisados }\end{array}$ \\
\hline $\begin{array}{l}\text { Conceito de } \\
\text { Função }\end{array}$ & $\begin{array}{l}\text { Analisar como é } \\
\text { apresentado o conceito } \\
\text { de Função nas atividades } \\
\text { propostas. }\end{array}$ & Dissertação & $\begin{array}{l}\text { Anos finais do } \\
\text { Ensino } \\
\text { Fundamental }\end{array}$ & $\begin{array}{c}\text { Material do } \\
\text { Ensino } \\
\text { Fundamental da } \\
\text { Rede Pública de } \\
\text { Ensino do Estado } \\
\text { de São Paulo }\end{array}$ \\
\hline
\end{tabular}




\begin{tabular}{|c|c|c|c|c|}
\hline & $\begin{array}{l}\text { Investigar a abordagem } \\
\text { de Função. }\end{array}$ & Dissertação & $\begin{array}{l}\text { Anos finais do } \\
\text { Ensino } \\
\text { Fundamental e } \\
\text { Ensino Médio }\end{array}$ & Livros didáticos \\
\hline & $\begin{array}{l}\text { Investigar o que tem sido } \\
\text { discutido, nos últimos } \\
\text { dez anos, sobre o ensino } \\
\text { e a aprendizagem de } \\
\text { função em pesquisas } \\
\text { brasileiras da área de } \\
\text { Educação Matemática. }\end{array}$ & Dissertação & $\begin{array}{l}\text { Anos finais do } \\
\text { Ensino } \\
\text { Fundamental e } \\
\text { do Ensino } \\
\text { Médio }\end{array}$ & $\begin{array}{c}\text { Artigos } \\
\text { publicados na } \\
\text { revista Educação } \\
\text { Matemática } \\
\text { Pesquisa }\end{array}$ \\
\hline $\begin{array}{l}\text { Função e } \\
\text { Modelagem } \\
\text { Matemática }\end{array}$ & $\begin{array}{lr}\text { Investigar } & \text { possíveis } \\
\text { contribuições } & \text { da } \\
\text { Modelagem Matemática } \\
\text { para o ensino de Função. }\end{array}$ & Dissertação & $\begin{array}{l}\text { Anos finais do } \\
\text { Ensino } \\
\text { Fundamental e } \\
\text { Ensino Médio }\end{array}$ & $\begin{array}{l}\text { Dissertações de } \\
\text { mestrado }\end{array}$ \\
\hline $\begin{array}{c}\text { Função } \\
\text { Exponencial }\end{array}$ & $\begin{array}{l}\text { Investigar como as } \\
\text { funções exponenciais } \\
\text { são abordadas. }\end{array}$ & Dissertação & Ensino Médio & $\begin{array}{c}\text { Livros didáticos } \\
\text { de Matemática } \\
\text { aprovados em } \\
2015 \text { pelo PNLD } \\
\end{array}$ \\
\hline
\end{tabular}

Fonte: elaborado pelos autores com base em dados da pesquisa.

Em relação aos aspectos gerais das investigações sobre Álgebra Linear apresentados no Quadro 12, notamos que todas as pesquisas focam no Ensino Superior, o que se justifica pela especificidade da temática. Notamos a ausência de investigações referentes a subtemas, como espaço vetorial, mudança de base, diagonalização de operadores, produto interno e utilização de conceitos de Álgebra Linear para a resolução de sistemas de equações diferenciais ordinárias. O subtema mais abordado é a noção de base. Há três pesquisas relacionadas à abordagem da Álgebra Linear em diferentes cursos de graduação (Licenciatura em Matemática e Engenharia Elétrica). Duas temáticas trabalhadas mais ao final de uma primeira disciplina de Álgebra Linear (transformação linear e autovalor e autovetor) foram alvo de estudos de duas das três teses desenvolvidas pelos integrantes do GPEA. Outro tema pesquisado foi independência linear. Em nenhuma pesquisa os processos de ensino e de aprendizagem de Álgebra Linear foram relacionados ao emprego de tecnologias. Cabe destacar e existência de projetos de pesquisa voltados exclusivamente ao ensino e à aprendizagem de Álgebra Linear, como evidenciado no Quadro 1.

Quadro 12 - Dissertações e teses sobre o conteúdo Álgebra Linear

\begin{tabular}{|c|c|c|c|c|}
\hline Conteúdo Matemático & Subtema & Dissertações & Teses & Total \\
\hline \multirow{4}{*}{ Álgebra Linear } & Noção de Base & 4 & 0 & 4 \\
\cline { 2 - 5 } & Álgebra Linear na Engenharia & 1 & 1 & 2 \\
\cline { 2 - 5 } & Independência Linear & 1 & 0 & 1 \\
\cline { 2 - 5 } & Álgebra Linear na Licenciatura & 0 & 1 & 1 \\
\hline
\end{tabular}




\begin{tabular}{|l|l|l|l|l|}
\hline & Transformação Linear & 0 & 1 & 1 \\
\hline \multicolumn{1}{|c|}{ TOTAIS } & $\mathbf{6}$ & $\mathbf{3}$ & $\mathbf{9}$ \\
\hline
\end{tabular}

Fonte: elaborado pelos autores com base em dados da pesquisa.

Como evidenciado no Quadro 13, as pesquisas experimentais sobre Álgebra Linear, pela própria natureza do tema, estão voltadas ao Ensino Superior. Há predomínio de dissertações (cinco) em comparação a teses (três). Em relação aos sujeitos de pesquisa, os estudos distribuem-se de maneira equilibrada: em quatro, os sujeitos são estudantes e em outros quatro, são professores. Os estudantes são de Engenharia Elétrica (um estudo), de Ciência da Computação (um estudo), de um curso de Extensão em Álgebra Linear (um estudo) e de Licenciatura em Matemática (um estudo). A respeito dos professores, sujeitos de pesquisa, há aqueles responsáveis por disciplinas específicas de um curso de Engenharia Elétrica (uma pesquisa), há os que atuam no Ensino Superior (duas pesquisas) e há os que são docentes no curso de Ciência da Computação (uma pesquisa). Os subtemas predominantes nas pesquisas experimentais realizadas pelos integrantes do GPEA são noção de base (quatro estudos) e Álgebra Linear na Engenharia (dois estudos). A respeito dos objetivos, em quatro pesquisas eles estão relacionados a como abordar a Álgebra Linear e ao que abordar sobre ela em cursos de graduação nos quais esse componente curricular está presente e cujos objetivos são distintos, como é o caso de Licenciatura em Matemática, Ciência da Computação e diferentes habilitações de Engenharia. Em um desses estudos com esse objetivo, o foco está em analisar as estruturas cognitivas envolvidas na construção de determinado objeto da Álgebra Linear (autovalor e autovetor). Há dois estudos que investigam possíveis "alavancas-meta" e "recursos meta" (ROBERT; ROBINET, 1993) a que recorrem professores de Álgebra Linear ao trabalhar com determinado conceito, e duas investigações cujo objetivo é identificar concepções de estudantes a respeito de determinados conceitos de Álgebra Linear. Finalmente, salientamos que não há pesquisas voltadas a outros cursos que não Ciência da Computação, Engenharia e Licenciatura em Matemática, que têm Álgebra Linear como componente curricular. Desse modo, identificamos uma demanda por investigações direcionadas a conteúdos matemáticos ainda não contemplados em pesquisas experimentais a que se refere o Quadro 13 e por estudos experimentais relacionados ao emprego de tecnologias nos processos de ensino e de aprendizagem de Álgebra Linear. 
Quadro 13 - Pesquisas experimentais sobre o conteúdo Álgebra Linear

\begin{tabular}{|c|c|c|c|c|}
\hline \multicolumn{5}{|c|}{ Conteúdo Matemático: Álgebra Linear - pesquisas experimentais } \\
\hline Subtema & Objetivo & $\begin{array}{c}\text { Tipo de } \\
\text { Produção }\end{array}$ & $\begin{array}{c}\text { Nível de } \\
\text { Ensino }\end{array}$ & Sujeitos \\
\hline $\begin{array}{l}\text { Álgebra Linear } \\
\text { na Licenciatura }\end{array}$ & $\begin{array}{l}\text { Investigar a Álgebra Linear } \\
\text { ensinada na Licenciatura em } \\
\text { Matemática como um saber } \\
\text { voltado para a formação do } \\
\text { professor de Matemática. }\end{array}$ & Tese & $\begin{array}{l}\text { Ensino } \\
\text { Superior }\end{array}$ & $\begin{array}{c}\text { Professores } \\
\text { do Ensino } \\
\text { Superior }\end{array}$ \\
\hline \multirow{2}{*}{$\begin{array}{l}\text { Álgebra Linear } \\
\text { na Engenharia }\end{array}$} & $\begin{array}{l}\text { Investigar por que e como deve } \\
\text { ser lecionada a Álgebra Linear } \\
\text { em uma graduação de } \\
\text { Engenharia Elétrica }\end{array}$ & Dissertação & $\begin{array}{l}\text { Ensino } \\
\text { Superior }\end{array}$ & $\begin{array}{l}\text { Professores } \\
\text { de } \\
\text { disciplinas } \\
\text { específicas } \\
\text { de } \\
\text { Engenharia } \\
\text { Elétrica } \\
\end{array}$ \\
\hline & $\begin{array}{lcr}\text { Investigar } & \text { as estruturas } \\
\text { cognitivas } & \text { envolvidas na } \\
\text { construção } & \text { do objeto } \\
\text { matemático } & \text { autovalor e } \\
\text { autovetor nas fases inicial e final } \\
\text { de formação do em cursos de } \\
\text { Engenharia }\end{array}$ & Tese & $\begin{array}{l}\text { Ensino } \\
\text { Superior }\end{array}$ & $\begin{array}{l}\text { Alunos dos } \\
\text { semestres } \\
\text { iniciais e dos } \\
\text { semestres } \\
\text { finais de } \\
\text { Engenharia }\end{array}$ \\
\hline \multirow{4}{*}{ Noção de Base } & $\begin{array}{l}\text { Investigar as "alavancas-meta" } \\
\text { sugeridas por professores de } \\
\text { Álgebra Linear para a } \\
\text { compreensão da noção de base. }\end{array}$ & Dissertação & $\begin{array}{l}\text { Ensino } \\
\text { Superior }\end{array}$ & $\begin{array}{c}\text { Professores } \\
\text { do Ensino } \\
\text { Superior }\end{array}$ \\
\hline & $\begin{array}{l}\text { Investigar como é utilizada a } \\
\text { noção de base de um espaço } \\
\text { vetorial em tópicos de Ciência } \\
\text { da Computação. }\end{array}$ & Dissertação & $\begin{array}{l}\text { Ensino } \\
\text { Superior }\end{array}$ & $\begin{array}{l}\text { Professores } \\
\text { do curso de } \\
\text { Ciência da } \\
\text { Computação } \\
\end{array}$ \\
\hline & $\begin{array}{l}\text { Investigar os "recursos-meta" } \\
\text { utilizados por um professor de } \\
\text { Álgebra Linear em sala de aula. }\end{array}$ & Dissertação & $\begin{array}{l}\text { Ensino } \\
\text { Superior }\end{array}$ & $\begin{array}{l}\text { Alunos do } \\
\text { curso de } \\
\text { Ciência da } \\
\text { Computação } \\
\end{array}$ \\
\hline & $\begin{array}{l}\text { Investigar a concepção de } \\
\text { alunos concluintes de um curso } \\
\text { de extensão de Álgebra Linear a } \\
\text { respeito da noção de base de um } \\
\text { espaço vetorial real finitamente } \\
\text { gerado. }\end{array}$ & Dissertação & $\begin{array}{l}\text { Ensino } \\
\text { Superior }\end{array}$ & $\begin{array}{l}\text { Alunos de } \\
\text { um curso de } \\
\text { extensão de } \\
\text { Álgebra } \\
\text { Linear }\end{array}$ \\
\hline $\begin{array}{c}\text { Transformação } \\
\text { Linear }\end{array}$ & $\begin{array}{l}\text { Investigar a concepção de } \\
\text { alunos de um curso de Álgebra } \\
\text { Linear a respeito de } \\
\text { Transformação Linear. }\end{array}$ & Tese & $\begin{array}{l}\text { Ensino } \\
\text { Superior }\end{array}$ & $\begin{array}{c}\text { Alunos de } \\
\text { licenciatura } \\
\text { em } \\
\text { Matemática } \\
\end{array}$ \\
\hline
\end{tabular}

Fonte: elaborado pelos autores com base em dados da pesquisa.

Sobre pesquisas documentais relativas a Álgebra Linear, destacamos apenas um trabalho. Trata-se de uma dissertação na qual são analisados livros didáticos, em particular os registros de representação semiótica utilizados na abordagem de independência linear. Tal fato revela que há inúmeros caminhos a serem trilhados por 
pesquisas futuras. Por exemplo, é possível analisar outros tipos de materiais, como apostilas, ou materiais de aula elaborados por professores, materiais de alunos (por exemplo, notas de aula), diretrizes curriculares nacionais de diferentes cursos em que a Álgebra Linear está presente como disciplina de serviço (por exemplo, Engenharias, Ciência da Computação, Física, Sistema de Informação, entre outros) e também o que é essencial em relação à Álgebra Linear nesses diferentes cursos de graduação. Outra possibilidade de estudo é analisar, se houver, pesquisas já realizadas acerca do emprego das Tecnologias Digitais de Informação e Comunicação nos processos de ensino e de aprendizagem de Álgebra Linear.

Quadro 14 - Pesquisas documentais sobre o conteúdo Álgebra Linear

\begin{tabular}{|c|l|c|c|c|}
\hline \multicolumn{6}{|c|}{ Conteúdo Matemático: Álgebra Linear - pesquisas documentais } \\
\hline Subtema & \multicolumn{1}{|c|}{ Objetivo } & $\begin{array}{c}\text { Tipo de } \\
\text { Produção }\end{array}$ & $\begin{array}{c}\text { Nível de } \\
\text { Ensino }\end{array}$ & $\begin{array}{c}\text { Documentos } \\
\text { Analisados }\end{array}$ \\
\hline \multirow{4}{*}{$\begin{array}{c}\text { Independência } \\
\text { Linear }\end{array}$} & $\begin{array}{l}\text { Investigar quais registros de } \\
\text { representação semiótica são } \\
\text { mais utilizados no estudo das } \\
\text { noções e atividades propostas } \\
\text { sobre independência linear. }\end{array}$ & Dissertação & $\begin{array}{c}\text { Ensino } \\
\text { Superior }\end{array}$ & $\begin{array}{c}\text { Livros didáticos } \\
\text { de Álgebra } \\
\text { Linear }\end{array}$ \\
\hline
\end{tabular}

Fonte: elaborado pelos autores com base em dados da pesquisa.

O tema Equações foi objeto de estudo de três dos projetos de pesquisa do GPEA, Concepções acerca de Relações (2006-2009), Expressões, equações e inequações: pesquisa, ensino e aprendizagem (2006-2010) e Funções do ponto de vista cognitivo e didático (2010-2013), apresentados no Quadro 1. Conforme os dados presentes no Quadro 15, o subtema mais explorado é Equações Algébricas (quatro trabalhos); os demais subtemas são contemplados de forma equilibrada. Com base nos dados apresentados, notamos a demanda por investigações relacionadas a outros tipos de equações, como as trigonométricas, exponenciais e diferenciais. Além disso, há possibilidades de estudo em relação à utilização de Tecnologias Digitais de Informação e Comunicação nos processos de ensino e de aprendizagem de equações.

Quadro 15 - Dissertações e teses sobre o conteúdo Equações

\begin{tabular}{|c|c|c|c|c|}
\hline Conteúdo Matemático & Subtema & Dissertações & Teses & Total \\
\hline \multirow{4}{*}{ Equações } & Equações Algébricas & 4 & 0 & 4 \\
\cline { 2 - 5 } & Equações no Ensino Médio & 1 & 0 & 1 \\
\cline { 2 - 5 } & Conhecimentos de licenciandos & 1 & 0 & 1 \\
\cline { 2 - 5 } & Significados da noção de equação & 0 & 1 & 1 \\
\cline { 2 - 5 } & Equações com TIC & 1 & 0 & 1 \\
\cline { 2 - 5 } & Equações e Inequações Logarítmicas & 1 & 0 & 1 \\
\hline TOTAIS & $\mathbf{8}$ & $\mathbf{1}$ & $\mathbf{9}$ \\
\hline
\end{tabular}

Fonte: elaborado pelos autores com base em dados da pesquisa. 
Considerando o Quadro 16, notamos apenas estudos de mestrado, os quais têm caráter experimental em relação ao tratamento de Equações. Os trabalhos realizados focam somente nas equações estudadas no currículo do Ensino Fundamental. Em relação ao nível de ensino, há predomínio de pesquisas voltadas aos anos finais do Ensino Fundamental (dois trabalhos) e há uma investigação voltada ao Ensino Superior; não há pesquisas relacionadas ao Ensino Médio. Sobre os sujeitos de pesquisa, todos são alunos: uns do $9^{\circ}$ ano do Ensino Fundamental (dois estudos), outros ingressantes no curso de Licenciatura em Matemática (um estudo). O subtema Equações Algébricas é o mais explorado (dois trabalhos). Em relação aos objetivos, eles são diferentes nas três pesquisas da categoria: em uma pesquisa, o objetivo é identificar erros, procedimentos e estratégias mobilizados por alunos, em outro, analisar o desempenho de alunos em questões de Álgebra (especificamente sobre equações) em uma avaliação externa (Sistema de Avaliação de Rendimento Escolar do Estado de São Paulo - Saresp) e, no seguinte, identificar conhecimentos sobre equações manifestados por estudantes ingressantes em cursos de Licenciatura em Matemática. Evidenciamos a demanda tanto por investigações experimentais que relacionem os processos de ensino e de aprendizagem de equações com a utilização de diferentes tecnologias digitais, incluindo softwares educativos, quanto por estudos voltados a outros tipos de equações que não as algébricas, como exponenciais, logarítmicas, trigonométricas e diferenciais.

Quadro 16 - Pesquisas experimentais sobre o conteúdo Equações

\begin{tabular}{|c|c|c|c|c|}
\hline \multicolumn{5}{|c|}{ Conteúdo Matemático: Equações - pesquisas experimentais } \\
\hline Subtema & Objetivo & $\begin{array}{c}\text { Tipo de } \\
\text { Producão }\end{array}$ & $\begin{array}{l}\text { Nível de } \\
\text { Ensino }\end{array}$ & Sujeitos \\
\hline \multirow[b]{2}{*}{$\begin{array}{l}\text { Equações } \\
\text { Algébricas }\end{array}$} & $\begin{array}{l}\text { Identificar os erros e analisar } \\
\text { procedimentos e estratégias que } \\
\text { os alunos utilizam para resolver } \\
\text { equações algébricas de } 1^{\circ} \text { grau. }\end{array}$ & Dissertação & $\begin{array}{l}\text { Anos finais } \\
\text { do Ensino } \\
\text { Fundamental }\end{array}$ & $\begin{array}{c}\text { Alunos do } 9^{\circ} \\
\text { ano }\end{array}$ \\
\hline & $\begin{array}{l}\text { Analisar o desempenho dos } \\
\text { alunos na resolução de algumas } \\
\text { questões do Saresp/2005 } \\
\text { relacionadas à Álgebra em } \\
\text { questões referentes a equações e } \\
\text { expressões envolvendo a } \\
\text { conversão da representação no } \\
\text { registro da língua natural para a } \\
\text { representação no registro } \\
\text { algébrico. }\end{array}$ & Dissertação & $\begin{array}{l}\text { Anos finais } \\
\text { do Ensino } \\
\text { Fundamental }\end{array}$ & $\begin{array}{c}\text { Alunos do } 9^{\circ} \\
\text { ano }\end{array}$ \\
\hline $\begin{array}{l}\text { Conhecimento } \\
\text { de Licenciandos }\end{array}$ & $\begin{array}{l}\text { Identificar os conhecimentos de } \\
\text { estudantes ingressantes na } \\
\text { Licenciatura em Matemática }\end{array}$ & Dissertação & $\begin{array}{l}\text { Ensino } \\
\text { Superior }\end{array}$ & $\begin{array}{c}\text { Alunos } \\
\text { ingressantes } \\
\text { em }\end{array}$ \\
\hline
\end{tabular}




\begin{tabular}{|l|l|l|l|l|}
\hline sobre equações. & & & $\begin{array}{c}\text { Licenciatura } \\
\text { em } \\
\text { Matemática }\end{array}$ \\
\hline
\end{tabular}

Fonte: elaborado pelos autores com base em dados da pesquisa.

Nas pesquisas documentais sobre Equações, apresentadas no Quadro 17, há predomínio de dissertações (cinco) em relação a teses (uma). As investigações enfocam o Ensino Médio (três) e os anos finais do Ensino Fundamental (duas). Em uma das pesquisas, a única de doutorado, o nível de ensino não foi explicitado, já que o objetivo do pesquisador era enfocar os significados da noção de equação, e não refletir acerca do ensino desse objeto em um nível específico. Em relação aos materiais analisados, a maior parte dos estudos recorreu a dissertações e teses publicadas em diferentes períodos (quatro trabalhos). Em uma pesquisa foram analisados textos diversos sobre Matemática e Educação Matemática, em outra, o Caderno do Professor da Secretaria de Educação do Estado de São Paulo para o Ensino Médio. O subtema predominante nessas pesquisas documentais é Equações Algébricas. Em relação aos objetivos, na maior parte dos trabalhos (quatro), eles estão voltados a sintetizar pesquisas já desenvolvidas a respeito do tema. Um trabalho tem como objetivo investigar os significados da noção de equação no ensino de Matemática, outro, analisar uma situação de aprendizagem proposta em um material oficial do Estado de São Paulo. Não foram desenvolvidas pesquisas com enfoque no material preparado pelo professor ou em notas de aulas de alunos, documentos oficiais, materiais que sugerem o uso de tecnologias digitais, currículos, projetos pedagógicos de cursos e diretrizes curriculares nacionais de diferentes cursos de graduação.

Quadro 17 - Pesquisas documentais sobre o conteúdo Equações

\begin{tabular}{|c|l|c|c|c|}
\hline \multicolumn{6}{|c|}{ Conteúdo Matemático: Equaçóes - pesquisas documentais } \\
\hline Subtema & \multicolumn{1}{|c|}{ Objetivo } & $\begin{array}{c}\text { Tipo de } \\
\text { Produção }\end{array}$ & $\begin{array}{c}\text { Nível de } \\
\text { Ensino }\end{array}$ & $\begin{array}{c}\text { Documentos } \\
\text { Analisados }\end{array}$ \\
\hline & $\begin{array}{l}\text { Realizar uma síntese de } \\
\text { pesquisas brasileiras que } \\
\text { tratam de equações } \\
\text { algébricas. }\end{array}$ & Dissertação & $\begin{array}{c}\text { Anos finais } \\
\text { do Ensino } \\
\text { Fundamental }\end{array}$ & $\begin{array}{c}\text { Dissertações de } \\
\text { mestrado } \\
\text { publicadas de 1998 } \\
\text { a 2004 }\end{array}$ \\
\cline { 2 - 5 } $\begin{array}{c}\text { Algébricas } \\
\text { Desenvolver um panorama } \\
\text { de dissertações sobre o } \\
\text { tema equações algébricas. }\end{array}$ & Dissertação & $\begin{array}{c}\text { Anos finais } \\
\text { do Ensino } \\
\text { Fundamental }\end{array}$ & $\begin{array}{c}\text { Dissertações } \\
\text { realizadas no } \\
\text { âmbito da PUC- } \\
\text { SP, publicadas } \\
\text { entre 2005 e 2008 }\end{array}$ \\
\hline $\begin{array}{c}\text { Equações no } \\
\text { Ensino Médio }\end{array}$ & $\begin{array}{l}\text { Realizar uma síntese de } \\
\text { pesquisas brasileiras que } \\
\text { tratam de equações. }\end{array}$ & Dissertação & Ensino Médio & $\begin{array}{c}\text { Dissertações e } \\
\text { teses produzidas } \\
\text { entre 1998 e 2006 }\end{array}$ \\
\hline
\end{tabular}




\begin{tabular}{|c|c|c|c|c|}
\hline $\begin{array}{l}\text { Significados } \\
\text { da Noção de } \\
\text { Equação }\end{array}$ & $\begin{array}{l}\text { Investigar os significados } \\
\text { da noção de equação no } \\
\text { ensino de Matemática. }\end{array}$ & Tese & Não há & $\begin{array}{c}\text { Textos diversos } \\
\text { sobre Matemática e } \\
\text { Educação } \\
\text { Matemática }\end{array}$ \\
\hline $\begin{array}{l}\text { Equações } \\
\text { com TIC }\end{array}$ & $\begin{array}{lr}\text { Fazer uma } & \text { síntese } \\
\text { dissertações } & \text { brasileiras } \\
\text { que tratam do ensino e da } \\
\text { aprendizagem } & \text { de } \\
\text { equações, recorrendo ao } \\
\text { uso de Tecnologias da } \\
\text { Informação } & \text { e } \\
\text { Comunicação. } & \\
\end{array}$ & Dissertação & Ensino Médio & $\begin{array}{c}\text { Dissertações } \\
\text { publicadas entre } \\
1998 \text { e } 2008\end{array}$ \\
\hline $\begin{array}{l}\text { Equações e } \\
\text { Inequações } \\
\text { Logarítmicas }\end{array}$ & $\begin{array}{l}\text { Analisar uma situação de } \\
\text { aprendizagem } \\
\text { equações e inequações } \\
\text { logarítmicas. }\end{array}$ & Dissertação & Ensino Médio & $\begin{array}{c}\text { Caderno do } \\
\text { Professor de } 2009 \\
\text { referente ao } \\
\text { terceiro bimestre } \\
\text { do primeiro ano do } \\
\text { Ensino Médio da } \\
\text { Rede Pública de } \\
\text { Ensino Estado de } \\
\text { São Paulo }\end{array}$ \\
\hline
\end{tabular}

Fonte: elaborado pelos autores com base em dados da pesquisa.

Tendo em vista a homologação da Base Nacional Comum Curricular (BNCC), em 14 de dezembro de 2017, ressaltamos que há demanda por análises relativas à proposta presente, direta ou indiretamente, em tal Base, no que se refere a quatro dos cinco temas mais privilegiados pelas pesquisas do GPEA, Números e Operações, Generalização de Padrões, Função e Equações, uma vez que Álgebra Linear é um tema específico do Ensino Superior. Além disso, entendemos ser necessário proceder ao exame de livros didáticos produzidos ou reformulados com base na BNCC, a fim de que seja possível compreender como os autores estão transpondo para os livros aquilo que é proposto no documento.

\section{Considerações finais}

Neste artigo, com base na análise de dissertações e teses produzidas pelos integrantes do GPEA, desde a sua criação, em 2003, até 2018, propusemo-nos a apresentar um mapeamento de alguns dos elementos abordados nesses estudos. A nosso ver, contemplamos o objetivo que apresentamos no início deste trabalho, qual seja, identificar os temas mais explorados nas investigações, bem como aqueles que demandam novos estudos e, especificamente, lacunas e caminhos ainda não trilhados, que podem constituir perspectivas para o desenvolvimento de investigações futuras 
tanto por parte de membros do próprio Grupo como por parte de pesquisadores em Educação Matemática.

Notamos que diversos temas ou conteúdos matemáticos foram estudados pelos pesquisadores do GPEA, indicando a permeabilidade da Álgebra em diferentes campos da Matemática. Neste artigo, detivemo-nos nos cinco conteúdos mais explorados: Números e Operações, Generalização de Padrões, Função, Álgebra Linear e Equações. Nestas considerações finais, optamos por sintetizar as principais lacunas no campo de estudo ou possibilidades para o desenvolvimento de novas investigações identificadas com base no exame desses conteúdos, o que passamos a expor.

Em relação ao tema Números e Operações, há ausência de estudos que enfoquem tanto números reais e complexos como o emprego de tecnologias, incluindo jogos digitais educativos. Em relação à pesquisa documental, há demanda por estudos relacionados à BNCC.

No que se refere ao conteúdo Generalização de Padrões, há lacunas relacionadas a investigações voltadas ao Ensino Superior, especialmente aos cursos de Licenciatura em Matemática, e ao tipo de material que poderia ser pesquisado, como notas de aulas, documentos oficiais (em particular a BNCC) e livros didáticos produzidos ou reformulados tendo a referida Base como subsídio. Há a possibilidade, ainda, de se investigar o emprego de tecnologia no ensino de generalização de padrões.

Em relação ao conteúdo matemático Função, há demanda por estudos relacionados às funções cosseno, tangente, cotangente, cossecante, racionais e respectivas funções inversas (quando houver), além de funções definidas por várias sentenças matemáticas. Outros caminhos possíveis de pesquisa são: investigar a aplicação do conceito de função em outras áreas do conhecimento; realizar pesquisas experimentais relacionadas a Função, com foco no Ensino Superior; verificar o emprego de tecnologias digitais no ensino. Em relação à pesquisa documental, pode-se analisar materiais preparados pelo o professor para ministrar aulas, documentos oficiais, ementas, planos de ensino, currículo, entre outros.

Quanto ao conteúdo matemático Álgebra Linear, há ausência de investigações referentes a subtemas como espaço vetorial, mudança de base, diagonalização de operadores, produto interno e utilização de conceitos de Álgebra Linear para a resolução de sistemas de equações diferenciais ordinárias. São necessárias, ainda, pesquisas voltadas a outros cursos, que não Ciência da Computação, Engenharia e Licenciatura em Matemática, os quais tenham Álgebra Linear como componente curricular. Estudos 
documentais contemplando apostilas, materiais elaborados por professores, anotações de aula produzidas por alunos, entre outros materiais, também podem ser desenvolvidos.

A respeito do conteúdo matemático Equações, são necessárias pesquisas que explorem outros tipos de equações além das algébricas, por exemplo, equações trigonométricas, exponenciais, logarítmicas e diferenciais. Além disso, há demanda por estudos que relacionem a utilização de tecnologias aos processos de ensino e de aprendizagem de equações. Como já ressaltado em relação a outros conteúdos matemáticos, há demanda por pesquisas documentais que tenham como foco diferentes materiais, além de livros didáticos, dissertações e teses.

Em decorrência da análise de todos os conteúdos matemáticos e temas abordados em pesquisas, percebemos a possibilidade de se desenvolver estudos que comparem as abordagens e os materiais didáticos utilizados em diferentes países.

A pesquisa evidenciou a importância de se realizar mapeamentos, como o que ora apresentamos, para indicar perspectivas para novos estudos e, assim, evitar repetições desnecessárias, que acabam por comprometer, em certa medida, o desenvolvimento da Educação Matemática, e, em especial, da Educação Algébrica, foco das produções do GPEA.

\section{Referências}

FIORENTINI, D.; PASSOS, C. L. B; LIMA, R. C. R. (Orgs.). Mapeamento da pesquisa acadêmica brasileira sobre o professor que ensina matemática: período 2001 - 2012. Campinas, SP: FE/UNICAMP, 2016.

ROBERT, A.; ROBINET, J. Prise en compte du méta en didactique des Mathématiques. Les cahiers de didactique des Mathematiques 21. Paris: Université Paris VII, DIDIREM, 1993. 